\title{
Arbor
}

\section{El Museo Naval y el Instituto de Historia y Cultura Naval}

\section{Fernando Riaño Lozano}

Arbor CLXXIII, 682 (Octubre 2002), 405-419 pp.

El autor de este artículo, director del Museo Naval y del Instituto de Historia y Cultura Naval, logra introducirnos en la historia de la Armada desde el siglo XVIII a través de unas pinceladas descriptivas de los principales fondos patrimoniales que se conservan en el Museo Naval, cuyas salas abarcan una temática realmente diversa y abrumadora: modelos de buques y arsenales, cartografía, colecciones documentales, instrumentos náuticos, iconografía, etnografía, medallística, numismática, vexilología, etc. etc.

Refleja también el artículo los origenes de estos fondos y su progresivo enriquecimiento a lo largo de los años, así como la paralela evolución de la configuración orgánica del Museo Naval, con especial relevancia del importante papel que desempeña su Patronato, auténtico motor de cuantas actividades se llevan a cabo.

Con respecto al Instituto de Historia y Cultura Naval, cuyos orígenes se encuentran en el seno del Consejo Superior de Investigaciones Científicas, se describe la ingente labor de investigación que se está realizando mediante publicaciones de carácter periódico, premios "Virgen del Carmen», trabajos monográficos, Revistas de Historia Naval, Jornadas de Historia Marítima, ciclos de conferencias, etc. etc.

En definitiva, ambos organismos, Museo e Instituto, son los depositarios e impulsores de la Armada para difundir en la sociedad española algo tan ligado a nuestra historia y condición como es la Cultura Naval. 


\section{Introducción}

Entre las opciones que se presentaban para hablar de estas dos instituciones, cuya misión principal es la de difundir y potenciar el conocimiento y acercamiento del pueblo español a la Armada y a todos los temas relacionados con la mar, se ha elegido -dada la limitada extensión de esta colaboración- la de darle un enfoque más bien divulgativo, con objeto de dar a conocer los orígenes, evolución, situación actual y proyectos del Museo y del Instituto, ambos ampliamente relacionados y prestigiados en el ámbito cultural que les es propio, pero siempre necesitados de más y mejor difusión.

\section{El Museo Naval y sus fondos patrimoniales}

El Museo Naval fue creado por Real Decreto de S.M. el Rey Carlos IV el 28 de septiembre de 1792, y puede por tanto considerarse esta iniciativa como una de las últimas consecuencias culturales de la Mustración, que tantos y tan prestigiosos representantes tuvo en la Real Armada.

Por desgracia, y a pesar de estar la Marina en su apogeo, la ocasión no fue tan favorable como parecía prometer. Los continuos enfrentamientos navales con Inglaterra, la Guerra de la Independencia, los conflictos de emancipación de las posesiones americanas, el nefasto reinado de Fernando VII y la Primera Guerra Carlista, configuran un dilatado y convulso período en el que por momentos la Armada llegó casi a desaparecer, y que impidió, lógicamente, llevar a cabo lo previsto en el Decreto de 1792.

Hay que esperar hasta el año 1843 para que, con medio siglo de retraso, se inaugure al fin el Museo en su primera sede del «Palacio de los Consejos». Pero poco duró en ese asentamiento, ya que dos años más tarde pasó a la llamada «Casa del Platero», que fue declarada en ruina en 1851 y originó su forzoso traslado a unas dependencias del «Palacio de los Ministerios», donde después de tan azaroso peregrinaje pudo reinaugurarse solemnemente por la reina Isabel II en noviembre de 1853. Allí continuó sin mayores sobresaltos hasta 1932, en que se trasladó al edificio del antiguo Ministerio de Marina, próximo a la plaza de Cibeles, donde, con algunas remodelaciones y ampliaciones importantes, continúa en la actualidad.

Volviendo a los orígenes, conviene reiterar que la decisión de crear el Museo supone la culminación de una política desarrollada a lo largo del siglo XVIII para potenciar todas las ramas del conocimiento aplicables a la Marina, mediante el establecimiento de centros educativos 
y científicos de alto nivel para la formación de oficiales: Real Compañía de Guardiasmarinas de Cádiz en 1717 (ampliada en el transcurso del siglo a Ferrol y Cartagena), Colegio de Cirugía de la Armada en 1748, Observatorio Astronómico de la Marina en 1753, Depósito Hidrográfico en 1770 y Escuela de Ingenieros de Marina en 1772.

Claro está que este proceso respondía armónicamente a otro similar de crecimiento de la Real Armada en buques, arsenales y astilleros, sin parangón histórico anterior o posterior.

Como ya se ha comentado, este excelente entorno material, científico y cultural debería haber favorecido el nacimiento de un espléndido «Museo de Marina», como así se denomina en el Decreto, para que..... «a más de la Biblioteca General reúna todas las Ciencias Naturales que son necesarias para la completa instrucción del cuerpo de la Armada y consiguiente utilidad ....». A pesar de que este momento de auge no pudo plasmarse en esa realidad, sí propició la formación de un substrato cultural y de amor a la tradición, que permitió, cincuenta años después, constituir el Museo con unos fondos iniciales numerosos y valiosísimos que habían sido ejemplarmente conservados en tiempos de grandes riesgos y penurias.

Estos primeros fondos del futuro Museo procedían de las Reales Compañías de Guardiasmarinas, los Arsenales y el Observatorio Astronómico, amén de algunos de origen más antiguo, preservados milagrosamente del desinterés y la incuria.

De forma aún más específica, se comisionó a diversos oficiales de la Armada para la compra de objetos y libros en distintos países europeos y para recopilar documentos diseminados por archivos oficiales y particulares de casas nobles, relacionadas de antiguo con nuestra historia marítima.

Tras el paso decisivo de la inauguración del Museo en 1843, se recuperaron con gran entusiasmo todos esos fondos mencionados y se nutrieron con nuevas aportaciones procedentes fundamentalmente de las colecciones reales -de ahí la espléndida serie de modelos de buques, arsenales y astilleros de los siglos XVIII y XIX- y también de donaciones de familias de honda raigambre marinera.

Es de obligada mención en este punto la existencia de un modelo de galeón flamenco datado en 1593, procedente de la Armería Real y depositado por orden de Isabel II. Se considera por tradición un obsequio de una embajada flamenca a Felipe II, y está reputado como único de su tipo del siglo XVI que se conserva en Europa.

Espigando entre los hechos más notables que jalonan el enriquecimiento progresivo de los fondos museísticos y archivísticos, hay que reseñar la incorporación a principios del pasado siglo de las riquísimas 
colecciones existentes en el extinto Depósito Hidrográfico, constituidas por manuscritos, planos, cartas náuticas, grabados y dibujos, y otras sobre navegación, astronomía y viajes.

Entre las joyas cartográficas se encuentra una pieza única en el mundo, la carta original elaborada por Juan de la Cosa en 1500, en la que por primera vez se reflejan las principales islas del Caribe y un nebuloso perfil de la Tierra Firme.

Las circunstancias que rodean a la adquisición de esta carta merecen ser comentadas: Fue presentada con toda probabilidad a los Reyes Católicos y depositada en la Casa de Contratación de Sevilla, desapareciendo de allí por causas nunca aclaradas, aunque el expolio napoleónico siempre está presente. De hecho, vuelve a documentarse su existencia, después de más de 300 años, al salir a subasta en París en 1832 y adquirirla el embajador de Holanda en esa capital. A la muerte de este propietario en 1853 es nuevamente subastada y adquirida por el Estado español a instancias del Ministro de Marina en la respetable cifra de 4.321 francos, quedando depositada en el Museo ese mismo año, hecho insólito de sensibilidad histórico-cultural en época tan poco propicia.

A esta carta de Juan de la Cosa hay que unir una serie muy valiosa de portulanos y atlas de los siglos XVI y XVII, como los de Mateo Prunes (1563) y Diego de Homen (1561), y los de Brunes, Ortellius, Waghenaer, Janssonius y Mercator. También es riquísima la cartografía del siglo XVIII, que reúne más de 7.000 cartas, casi todas manuscritas, y entre ellas una colección muy completa y singular de las costas americanas.

Igualmente proceden del Depósito Hidrográfico la serie de colecciones de documentos sobre temas navales, de extraordinario valor y reunidas con gran celo y competencia por una serie de eruditos oficiales de Marina de los siglos XVIII y XIX, por lo que llevan su nombre: Fernández de Navarrete, Sanz de Barutell, Vargas Ponce, Zalvide y Vázquez de Figueroa. Aunque han sido incorporadas con posterioridad, y por tanto no proceden del Depósito, conviene mencionar también otras importantes colecciones donadas por los oficiales que las constituyeron o por sus descendientes. Así la de Enrile en 1935, la de Fernández Duro en 1939, la de Cincunegui en 1960 y la de Mazarredo en 1973. Por último, son prácticamente contemporáneas, las de Guillén y González-Aller, ésta última con su recopilador aún en plena actividad.

Ha sido obligado detenerse con algo más de detalle en este tema de las colecciones documentales, para subrayar el enorme interés histórico de estas recopilaciones y la vitalidad de este encomiable proceso, 


\section{El Museo Naval y el Instituto de Historia y Cultura Naval}

llevado a cabo con entusiasmo y sacrificio por profesionales de la Armada durante más de dos siglos.

Siguiendo este procedimiento descriptivo de dar pinceladas un poco anárquicas para destacar las piezas más relevantes, es preciso hacer mención de los instrumentos náuticos que, lógicamente, tienen una importante presencia en el Museo. Las colecciones de astrolabios astronómicos, cuadrantes, octantes, sextantes, brújulas, «agujas de marear», «relojes de longitud», cronómetros marinos, catalejos, relojes de sol y esferas armilares y celestes, constituyen un muestrario de primer orden.

Pueden mencionarse, en particular, el Estuche Instrumental de Felipe II fabricado por Wolkmer en 1596, el Estuche de Navegación obra de Pierre du Jardin de 1645, los astrolabios astronómicos, uno anónimo fechado en 1563 y otro firmado por Miguel Coignet en 1598......, y así podría citarse una dilatada lista que haría la relación interminable.

En el campo de la iconografía, óleos, acuarelas, dibujos y grabados, el Museo posee unos fondos muy interesantes, aunque menos espectaculares que los hasta ahora descritos. En la pintura del siglo XVII, su principal apoyatura son los óleos cedidos en depósito por el Museo del Prado, y entre ellos los referidos a batallas navales hispano-holandesas de Juan de la Corte.

En el siglo XVIII el censo de marinistas españoles fue escasísimo y hubo que aguardar al notable plantel surgido en el XIX y principios del XX para enriquecer de forma importante estos fondos. Factor básico fue la figura de "pintor-restaurador del Museo", creada desde época muy temprana y que fue cubierta sucesivamente por expertos en temas navales tan notables como Monleón, Cortellini y Caula, y ya en el siglo XX por García Condoy. También Brugada, posiblemente el mejor marinista del XIX, sin estar directamente contratado por el Museo, trabajó con frecuencia para él, dejando una sobresaliente obra pictórica que ha seguido incrementándose hasta fechas recientísimas.

Otro tipo de colecciones sorprendentes por su exotismo e importancia son las que se encuentran en la "Sala de Etnografía». Gracias al celo y desprendimiento de una serie de oficiales ilustrados destinados en Filipinas se fueron recibiendo donaciones de colecciones particulares, que acabaron constituyendo unos fondos de armas ofensivas y defensivas, modelos de embarcaciones y objetos diversos de Filipinas, Extremo Oriente e Islas del Pacífico, de un valor verdaderamente notable.

Existen también colecciones de medallística y numismática muy enfocadas a la temática naval y por tanto interesantes dentro de su especialización.

La vexilología no tiene una especial relevancia dentro de la zona expositiva del Museo, pero sí se preservan y restauran todas las ban- 
deras y uniformes que tienen entrada en las colecciones. En este punto es obligado mencionar la existencia de dos piezas excepcionales que realzan por sí solas la colección:

- El Estandarte Real de los Oquendo, de finales del siglo XVI, que tiene unas dimensiones de aproximadamente tres y medio por cuatro metros y es de seda adamascada. Está pintado al óleo con el escudo real de Felipe II y motivos religiosos. El estandarte lleva vaina para driza con objeto de ser izado en la mar. Pudo haber sido utilizado por el almirante Miguel de Oquendo, por su hijo Antonio también glorioso almirante, o por ambos. Se encuentra en el Museo desde 1991, depositado por su propietario el Duque del Infantado, procedente de su casa solariega de Lazcano en Guipúzcoa, y actualmente se le está realizando una completa restauración en el taller de textiles del Museo.

- El Repostero de la casa ducal de Fernán Núñez, de seda adamascada roja y grandes dimensiones $(6,80 \times 8,65 \mathrm{~m})$, que fue pintado al óleo hacia 1690 por Meneses -discípulo aventajado de Murillo-, por encargo del conde de Fernán Núñez, capitán general de la Armadas del Mar Océano. El encargo tenía por objeto recubrir dignamente un trofeo de Lepanto, la vela de una galera turca apresada por un antepasado. Fue donado al Museo en 1986 por el duque de Fernán Núñez y por su hermana la duquesa de Arco.

No se debe finalizar este apresurado repaso sin mencionar una sala muy especial, en la que se contienen importantes piezas recuperadas de un hallazgo submarino. Se trata del galeón español San Diego, hundido en combate con buques holandeses en 1601 cerca de Manila, cargado de mercaderías para el tráfico con Acapulco. El hallazgo lo realizó un buceador francés, y aproximadamente una tercera parte de las piezas extraídas -cañones de bronce, armas, municiones, variados objetos de uso cotidiano a bordo, vasijas y cántaras orientales de todo tipo, así como una extraordinaria colección de porcelana china Ming- son las que se exhiben en el Museo, en calidad de depósito, donación o dación al Estado.

Naturalmente, todo lo expuesto hasta aquí se refiere a la sede madrileña del Museo Naval, que constituye sólo una parte, aunque muy importante, de su patrimonio total, que está formado además por todos los objetos, libros y documentos depositados en:

- El Panteón de Marinos Ilustres de San Fernando (Cádiz).

- Los Museos de las Zonas Marítimas, con sede en edificios navales históricos de Ferrol, San Fernando, Cartagena y Las Palmas de Gran Canaria. 


\section{El Museo Naval y el Instituto de Historia y Cultura Naval}

- El Archivo-Museo «Don Álvaro de Bazán», en el Palacio del Marqués de Santa Cruz, de El Viso del Marqués (Ciudad Real).

- El Museo Marítimo de la «Torre del Oro», de Sevilla.

- Los fondos de valor histórico-artístico depositados en los centros, dependencias y unidades de la Armada.

Más adelante se incidirá nuevamente en este asunto para describir la estructura orgánica y de dependencias en que están configurados todos estos centros, llamados periféricos, que constituyen, se insiste en ello, parte integral del ente orgánico «Museo Naval».

Lógicamente, por razones de capacidad y representatividad, la sede de Madrid asume las principales responsabilidades. En concreto, y en los aspectos más puramente museísticos, en ella se concentran los mayores medios de restauración, representados por acreditados gabinetes y talleres de pintura, textiles, papel y encuadernación, modelismo naval, armas y ebanistería. Este considerable potencial permite atender también las necesidades más especializadas de los centros periféricos.

Asimismo, en las instalaciones de Madrid se atienden y canalizan la inmensa mayoría de las consultas que se efectúan a los fondos documentales, bibliográficos, cartográficos, etc., para lo que se dispone de una Sala de Investigadores y una Cartoteca.

Aunque, como ya se ha señalado, una gran parte de los fondos patrimoniales se encuentra distribuida por las instituciones y centros periféricos, puede resultar indicativo dar unas cifras sobre los existentes en la sede de Madrid:

- Piezas exhibidas del patrimonio museográfico, del orden de 10.500 .

- Cartografía, 7.000 mapas manuscritos y 500 atlas grabados.

- Manuscritos, 3.000 legajos o cajas que contienen aproximadamente 100.000 documentos.

- Biblioteca especializada, más de 23.000 volúmenes.

- Archivo fotográfico, más de 72.000 imágenes.

- Planos de buques, del orden de 1.300 de los siglos XVII al XX.

- Estampas calcográficas y dibujos originales, 1.350 de los siglos XVII y XVIII.

- Folletos singulares de los siglos XVI a XVIII, 6.135

Como más significativo en cifras, fuera de la capital, cabe señalar que sólo en el Archivo General de la Marina «Don Álvaro de Bazán» existen unos 17 kilómetros de estanterías, que contienen los fondos documentales de la Armada desde mediados del siglo XVIII. 
Una actividad fundamental de toda institución cultural, y más si se trata de un museo, es la de organizar exposiciones en su propio recinto, o colaborar con la iniciativa de otros aportando los fondos más adecuados para lograr la difusión y prestigio propios y la máxima brillantez del evento a celebrar. En este sentido, el Museo Naval, desde su creación, ha mantenido una decidida política de aportación y cooperación en exposiciones ajenas, a las que por cierto ha sido tradicionalmente muy requerido.

Ya en 1855, sólo doce años después de su inauguración, el gobierno francés invitó al Museo Naval a participar en la Exposición Universal de París. Fue la primera concurrencia a una exposición extranjera, y debió ser buena la experiencia pues volvió a participar en las celebradas en los años 1867 y 1877. Desde entonces la actividad ha sido continua y los fondos del Museo, de mayor o menor entidad y categoría, se han paseado en infinidad de ocasiones por toda España, multitud de veces por Europa, con frecuencia por América del Norte y del Sur, y en alguna rara oportunidad por Extremo Oriente, Japón y Australia.

Otra actividad ineludible es la de editar todo lo que contribuya a la mejor difusión y actualización de los fondos patrimoniales, y también en esta faceta el Museo Naval ha tenido -y tiene- una relevante actividad, sobre todo a partir del primer tercio del siglo XX. Como sería absurdo intentar siquiera una enumeración de las obras directamente publicadas, propiciadas o impulsadas de forma decisiva por el Museo, hay que limitarse simplemente a trazar un bosquejo de las personalidades, circunstancias culturales y conmemoraciones principales, que han ido configurando su política editorial.

Después de un prolongado período en el que las ediciones del Museo se limitaron prácticamente a la actualización periódica de un modesto, aunque riguroso catálogo, el primer impulso importante lo llevó a cabo el que sería su director durante casi cuarenta años, el almirante Guillén Tato -el inolvidable Don Julio- que dejó una huella imborrable en la Armada. Su portentosa erudición y capacidad de trabajo -fue académico y secretario perpetuo de la Real Academia de la Historia- le capacitaron para escribir sobre cualquier tema de la historia naval. Ninguna inquietud cultural le fue ajena a esta irrepetible figura, cuyas obras inundan el dilatado período comprendido entre 1928 -fecha de su primera publicación «Los marinos que pintó Goya»- y la de su fallecimiento en 1973.

Con este poderoso impulso, las publicaciones se multiplican y alcanzan cotas realmente notables, especialmente con ocasión de las grandes conmemoraciones históricas: 1971 Cuarto Centenario de Lepanto, 
1988 Cuarto Centenario de la Gran Armada, 1992 Quinto Centenario por antonomasia, y 2000 Quinto Centenario del nacimiento de Carlos V. En paralelo con ello se emprende una importantísima campaña de ediciones facsimilares de los principales libros de navegación y cosmografía de autores españoles del siglo XVI, y de las obras más importantes del gran historiador y marino del siglo XIX don Cesáreo Fernández Duro, también, como Guillén, académico y secretario perpetuo de la Academia de la Historia.

«La Expedición Malaspina», en nueve tomos extraordinariamente editados; la rigurosa y dilatada obra del prestigioso historiador, marino y antiguo director del Museo capitán de navío Cerezo Martínez; la ya extensa y enjundiosa obra del almirante González-Aller, director también del Museo durante un espléndido período de nueve años; los notables estudios históricos y cartográficos de Dolores Higueras, actual directora técnica;... todas estas obras constituyen, en fin, sólo una parte de los planes editoriales, llevados a cabo con ilusión y competencia por los miembros del personal facultativo del Museo, y por algunos entusiastas colaboradores, cuya mención resulta imposible.

Quedaría incompleta esta apresurada exposición si no se resaltase de forma expresa a un organismo de la mayor representatividad e importancia para el Museo: el Patronato.

\section{El Patronato del Museo Naval}

En 1932, el mismo año de la instalación del Museo en su actual sede, se crea el Patronato del Museo Naval, siendo su primer presidente el marqués de Santa Cruz, y uno de los vocales el duque de Veragua.

Desde el principio el Patronato se muestra especialmente activo y eficaz, y así en 1933 propone la instalación de un Museo Marítimo, dependiente del Naval de Madrid, en la Torre del Oro de Sevilla, antigua sede de la Comandancia de Marina del Guadalquivir, autorizándose la propuesta en 1936.

Después de la Guerra Civil continúa el Patronato con importantes iniciativas, destacando de manera singular sus gestiones para conseguir la cesión por parte del marqués de Santa Cruz de su palacio de El Viso, para la instalación del Archivo-Museo «Don Álvaro de Bazán». El contrato de arrendamiento con la Armada tiene una duración de noventa años al precio anual de una peseta, por lo que al entrar este año en la era euro, y para no alterar la tradición, ha sido necesario efectuar acopio de esos antiguos billetes hasta el año 2040. 
Otro hito determinante en la marcha del Patronato fue la designación en 1982 como Presidente de S.A.R. don Juan de Borbón y Battemberg, conde de Barcelona y Capitán General de la Armada.

Al fallecer Don Juan en 1993, después de un fructífero período de diez años en los que dio cumplida muestra de su proverbial amor a la Armada, fue designado para relevarle S.A.R. don Carlos de Borbón Dos Sicilias, duque de Calabria, que continúa como actual Presidente del Patronato.

Se considera conveniente en este punto transcribir los aspectos más relevantes de la base legislativa que sustenta a esta institución, el «Reglamento del Museo Naval y su Patronato», aprobado por Real Decreto de 1 de marzo de 1996. Se trata de una reglamentación modélica, que define al Museo como una entidad de titularidad estatal, bajo dependencia orgánica del Jefe del Estado Mayor de la Armada, y con dependencia funcional de la Dirección General de Relaciones Institucionales del Ministerio de Defensa. Su misión consiste en adquirir, conservar, investigar, comunicar y exhibir para fines de estudio, educación y contemplación, piezas, conjuntos y colecciones de valor histórico, artístico, científico y técnico relacionados con la actividad naval, a fin de difundir la historia marítima de España, contribuir a ilustrar, relevar, y salvaguardar sus tradiciones y promover la conciencia marítima nacional. La redacción no puede ser más clara y completa.

También determina que los órganos rectores del Museo serán el Patronato y la Dirección, actuando como órgano asesor la Junta de Gobierno. Al Patronato lo define como «el órgano de alta dirección» y prescribe cómo debe estar constituido.

Ya se ha comentado que las dos últimas personalidades que han ocupado la presidencia han sido destacados miembros de la Familia Real. El reglamento, por supuesto, no dice nada al respecto, pero se trata de una tendencia afortunada y coherente con la trayectoria del Museo, que desde su origen ha contado con el amparo y el respaldo de la Casa Real.

La especificación de los vocales natos está cuidadosamente aquilatada. Figuran en primer lugar tres títulos de nobleza con Grandeza de España y honda raigambre marinera: el duque del Infantado Almirante de Aragón, el marqués de Santa Cruz, y el duque de Veragua, Almirante y Adelantado Mayor de las Indias. El Ministerio de Defensa está representado por el Director General de Relaciones Institucionales, y la Armada por los Almirantes de las Zonas Marítimas, el de la Flota y el Director del Museo Naval.

Asimismo, los vocales por designación pertenecen a tres instituciones y organismos cuya naturaleza y fines concuerdan con los del Museo: 
un miembro numerario de la Real Academia de la Historia, otro miembro numerario de la Real Academia de Bellas Artes de San Fernando, y un representante de la Dirección General de Bellas Artes, quedando además abierta la posibilidad de otras designaciones, también de carácter institucional, que el Patronato pudiera considerar convenientes.

Por último, se dispone la designación de un número máximo de cinco vocales, a título personal, entre personas de destacado relieve cultural en temas relacionados con la Marina, la Historia o las Artes.

Tras esta descripción detallada de la composición del Patronato, hecha intencionadamente por tratarse del auténtico motor e imprescindible apoyo con que cuenta el Museo, es obligado hacer referencia a otro importante organismo, el Instituto de Historia y Cultura Naval, cuya responsabilidad corresponde también al director del Museo, y que constituye el complemento esencial para el desarrollo de las múltiples actividades que se llevan a cabo en el ámbito que nos ocupa.

\section{El Instituto de Historia y Cultura Naval}

En 1942, por Decreto de la Presidencia del Gobierno se constituye, en el marco del Consejo Superior de Investigaciones Científicas y con sede en el Museo Naval, el Instituto Histórico de la Marina. Fue promotor de la idea y primer director de la nueva institución el almirante Guillén, en destino compartido con el del Museo.

Este organismo fue el antecedente próximo del Instituto de Historia y Cultura Naval, creado por Real Decreto en 1976 y reorganizado en el año 2000.

Antes de seguir adelante, se debe subrayar que la génesis remota de este organismo fue en el seno del Consejo Superior de Investigaciones Científicas. Esta curiosa circunstancia será poco conocida por los lectores de la revista ARBOR, y se estima que este entronque común tiene una especial significación cultural y afectiva que trasciende la mera anécdota pero nos desviaría en exceso el tratar de profundizar en esta reflexión.

Otro antecedente histórico destacable, aunque en este caso no se trató de una evolución orgánica sino de una absorción, fue la incorporación del Instituto del Patronato de los Premios «Virgen del Carmen».

Dicho Patronato fue creado inmediatamente después de finalizada la Guerra Civil, y aunque su finalidad estaba claramente expresada, -luchar contra el tradicional desinterés del español por la mar-, la ejecución del decreto se expresaba de forma bastante confusa, tratando de asignar los premios recién creados a «aquellos núcleos de población 
costera más inmediata y directamente afectados». Lógicamente se refería a verse «afectados» por el desinterés marinero general, pero quedaba poco claro, y menos aún el asignárselo a algo tan inconcreto como los «núcleos de población costera». Se trataba sin duda de los primeros balbuceos y son disculpables estas inconcreciones.

$\mathrm{El}$ proceso poco a poco se fue perfeccionando y ya en 1945 se premian «las actividades de carácter social, técnico, artístico, literario, cultural, docente, divulgador o deportivo, que se relacionen con el mar y sus problemas y sirvan para fomentar la afición marítima». Como se ve los temas eran variadísimos, sin duda por depender el Patronato de la Presidencia del Gobierno y contemplar también las actividades de la Marina Mercante, Pesquera y Deportiva.

Esta situación continúa hasta 1974 en que el Patronato pasa a depender del Ministerio de Marina, y en 1975 del Jefe del Estado Mayor de la Armada, por delegación del Ministro de Defensa. A partir de esta circunstancia, la entrega de premios adquiere una característica especial, la de llevarse a cabo en ciudades alejadas del litoral para llevarles «el mensaje del mar» mediante un solemne acto académico. Valladolid, Zaragoza, Mérida, Cuenca, Almagro... y hasta trece ciudades más del interior, recibieron cada año la visita amistosa, e incluso un poco exótica por lo desconocida, de la Armada. Este ciclo itinerante finalizó en 1991, año en el que el Instituto de Historia y Cultura Naval asumió las competencias del Patronato, después de más de cincuenta años de labor, siempre ilusionada, en pro de la cultura naval.

Los premios actuales son los siguientes, en denominación, naturaleza y cuantía económica:

- «Del Mar», para libros, dotado con $6.000 €$

- «Poesía del Mar», para el mejor poema o colección de poemas, $1.800 €$

- «Juventud Marinera», para alumnos entre 10/16 años, equipo completo de informática

- «Armada de Pintura», $1^{\text {er }}$ Premio $7.500 € 2^{\circ}$ Premio $3.000 €$

Se convocan anualmente en los meses de enero/febrero, con publicación en el Boletín Oficial del Estado y en el de Defensa; la designación de los premiados se realiza el día 16 de julio, festividad de nuestra Patrona la Virgen del Carmen; y la entrega de los premios se efectúa en acto solemne en el Cuartel General de la Armada entre los meses de octubre y noviembre.

Comentados estos antecedentes principales, es el momento de describir cuáles han sido los planteamientos, logros y proyectos del Instituto en su configuración actual. 
Ya se ha dicho que su creación data del año 1976, pero los primeros frutos consistentes no empiezan a consolidarse hasta la década de los años ochenta. El primer gran proyecto fue el de la celebración del IV Centenario de la Empresa contra Inglaterra de Felipe II en 1588. Los primeros trabajos de planificación, constitución de grupos de investigadores y adecuada dotación presupuestaria se emprendieron en 1980, organizándose siete comisiones integradas por historiadores civiles y oficiales de la Armada, a las que se encomendó el estudio de diferentes aspectos del proyecto que se denominó «Gran Armada». El trabajo fue riguroso y exhaustivo, con el resultado final de la edición de nueve monografías y un trabajo monumental denominado la «Batalla del Mar Océano», del que hay ya cinco tomos publicados y al menos otros tres pendientes de conclusión.

La labor de investigación fue ingente y salieron a la luz miles de manuscritos, absolutamente desconocidos, que permitieron contemplar tan controvertido y deformado hecho histórico con un respaldo documental aplastante y unas conclusiones muchas veces novedosas y en ocasiones espectaculares. El éxito fue ampliamente reconocido y alabado por los más prestigiosos historiadores británicos en un simposio celebrado en 1988, con sede sucesivamente en Londres y Madrid.

El segundo proyecto de investigación fue también de largo aliento. Se denominó en principio "Islario del Pacífico» y fue realizado exclusivamente por oficiales de la Armada. Se trataba de esclarecer los viajes y descubrimientos españoles en aquel océano, identificando las derrotas seguidas por nuestros navegantes y la verdadera identidad de cada una de las islas. Los trabajos comenzaron en 1985 y se plasmaron en tres magníficos tomos de gran formato y enjundioso contenido, publicados en 1992 con el título de «Descubrimientos españoles en el Mar del Sur».

También de la década de los ochenta datan dos iniciativas que han tenido una fructífera continuidad en el tiempo y han acabado constituyéndose en los dos principales pilares en los que se asienta la actividad cultural y difusora del Instituto: la Revista de Historia Naval y las Jornadas de Historia Marítima.

El primer número de la revista se publicó en 1983 con la intención de ser el órgano a través del cual se dieran a conocer los trabajos de los estudiosos y eruditos en historia naval y, además, servir de catalizador cultural para atraer la atención sobre determinadas conmemoraciones o eventos históricos relacionados con la Armada.

Se trata de una publicación trimestral que ha cumplido con su compromiso y está a punto de celebrar los veinte años de existencia 
ininterrumpidos, plasmada en 75 números que han servido de foro $\mathrm{y}$ portavoz de todos los que aman este campo apasionante de la historia.

En cuanto a las Jornadas de Historia Marítima, dentro de este título se pretende englobar toda una serie de actos culturales, tales como simposios, jornadas de política marítima, jornadas de historiografía, conferencias monográficas sobre determinados temas de interés cultural y, mayoritariamente, las mencionadas Jornadas de Historia Marítima, que por ser las más numerosas y sistematizadas han marcado el carácter de este tipo de actos.

Generalmente se suelen celebrar en Madrid, en el Salón de Actos del Cuartel General de la Armada, con una frecuencia de dos anuales -primavera y otoño- y una duración de tres días en sesión vespertina.

Las primeras Jornadas se realizaron en 1987 y tuvieron por título «España y el Ultramar Hispánico hasta la Ilustración» y las últimas, que hacían el número XXII, trataron sobre «La Casa de Contratación de Sevilla».

La selección de este último tema merece ser comentada porque puede servir de ejemplo ilustrativo sobre las pautas de actuación del Instituto. Cuando se estaban diseñando las actividades culturales para el año 2001 se detectó la cercanía del $500^{\circ}$ aniversario de la creación, en 1503, de la mencionada Casa de la Contratación, de carácter único por su versatilidad, pero en todo y sobre todo influida por la mar en su nueva y desmesurada dimensión oceánica. Consecuente con ello, se programaron para el mes de octubre una serie de conferencias, con la colaboración de prestigiosos miembros de la universidad sevillana, con objeto sobre todo de servir de desencadenante de los actos conmemorativos que tan importante efemérides merecía, y sobre los que, una vez provocada la inquietud, se ha cedido, como debe ser, la iniciativa y protagonismo a las instituciones culturales hispalenses.

Todo este proceso consolidado de organización de ciclos de conferencias, tiene el valor añadido de la publicación sistemática de cuadernos monográficos en los que se recogen las conferencias impartidas. En el devenir de los años, gracias a la calidad de los autores y al interés y variedad de los temas, este tipo de publicaciones constituye un sólido y valioso fondo histórico, con un ámbito de difusión relativamente importante. Hasta el momento se han editado 39 cuadernos monográficos de esa naturaleza y otros 4 números de carácter extraordinario.

También, dentro del campo de las publicaciones, es responsabilidad del Instituto promover e impulsar los trabajos de investigación de interés para sus fines, y elaborar la propuesta de inclusión de estas obras en el Programa Editorial del Ministerio de Defensa. Por este proce- 


\section{El Museo Naval y el Instituto de Historia y Cultura Naval}

dimiento se editan anualmente de dos a cuatro libros, entre los que figuran, además de autores pertenecientes a la Armada, numerosos historiadores y eruditos de estamentos civiles.

No se debe terminar sin hacer una breve referencia a la organización del Instituto, que como ya se señaló anteriormente, se basa en una Orden Ministerial de marzo de 2000, y tiene por tanto apenas dos años.

La estructura, dependencias y misión están muy influidas por la legislación que rige al Museo Naval, que la antecede en cuatro años y tiene además rango de Real Decreto. Se trata pues de una normativa muy contrastada que se ha implantado con buenos resultados, cuyos aspectos más reseñables, por salirse de la orgánica normal, son las posibilidades que brinda de obtener refuerzos adicionales de personal mediante dos vías: los asesores de la Dirección y los consejeros-colaboradores del Instituto. Esta fórmula permite contar con apoyos oficializados de personas capaces y afectas a la Institución, siempre necesitada de este tipo de colaboraciones.

Otro detalle orgánico interesante es el de instituir una red de Delegaciones del Instituto en las Zonas Marítimas. En este momento los delegados en ejercicio son tres, con sede en Ferrol, Cartagena y San Fernando (Cádiz), y su cargo coincide con el de conservador de los respectivos museos -llamados periféricos- allí basados. También está en fase muy avanzada la constitución del Museo Naval de la Zona Marítima de Canarias, y su conservador será asímismo delegado del Instituto.

Queda, por último, reiterar que la responsabilidad de las actividades del Museo y del Instituto confluyen en una sola persona, su director. Con ello se trata fundamentalmente de concentrar y optimizar la gestión de los siempre limitados recursos de personal y presupuestarios. Si bien es verdad que estas tradicionales escaseces, se ven afortunadamente paliadas por el apoyo de todo orden recibido de particulares y organizaciones que día a día se afanan en desmentir el desinterés del español por las cosas de la mar. Aunque los avances sean lentos, lo importante es seguir avante con ánimo y confianza, conscientes de que se está en el buen rumbo. 